\title{
PEMILIHAN FIXED HEAD ATAU FREE HEAD DALAM DESAIN FUNDASI TANGKI REAKTOR KAP. 2000 M3 PILOT PLANT BIOGAS POME SETARA 700 KW DI PTPN V RIAU
}

\author{
oleh : \\ Samdi Yarsono, Lan Marrakup TN, Ika Wulandari, Eva Nur Septinia, Giman \\ Balai Teknologi Bahan Bakar dan Rekayasa Desain, BPPT \\ Email : samdi.yarsono@bppt.go.id \\ Mohammad Imamuddin, Juda Suwandi, Basit Al Hanif \\ Teknik Sipil Universitas Muhammadiyah Jakarta \\ Email : imamuddin@umj.ac.id
}

\begin{abstract}
Abstrak : Kebutuhan energi terbarukan di Indonesia sangatlah penting, saat ini sumber energi terbarukan porsinya relatif kecil. BPPT ( Badan Pengkajian dan Penerapan Teknologi) dalam kegiatannya melakukan pembangunan pilot plant Biogas Pome setara $700 \mathrm{~kW}$ berkerjasama dengan PTPN V (PT. Perkebunan Nusantara V) dengan sistim tangki berpengaduk secara kontinu yang mana hasil gas tersebut dimanfaatkan sebagai bahan bakar boiler pabrik PMKS di sei pagar. Metode pemilihan pondasi tangki reaktor dengan kapasitas $2000 \mathrm{~m} 3$, kami melakukan perbandingan perhitungan antara menggunakan free head atau fix head dengan memakai diameter $50 \mathrm{~cm}$ dan $60 \mathrm{~cm}$ dengan melihat banyaknya jumlah, diameter pile dan ketebalan mat yang digunakan. Diameter rencana tangki reactor direncanakan berukuran 16.8m dengan ketinggian 9m, dengan beban tangki sekitar 2174.2ton dan berdasarkan data dari soil test didapat nilai N-SPT di kedalaman 10-15m, untuk itu kami merumuskan bahwa fundasi pile yang kita pilih. Perbandingan fix and free head pada pile ukuran $50 \mathrm{~cm}$ dimana perbedaan fix and free head 44 berbanding 65 , dengan ketebalan mat foundation $1.1 \mathrm{~m}$ berbanding $0.6 \mathrm{~m}$ sedangkan dengan mengunakan diameter $60 \mathrm{~cm}$ jumlah pile 32 berbanding 50 dengan ketebalan mat $1.3 \mathrm{~m}$ berbanding $0.6 \mathrm{~m}$. Dari analisa tersebut dengan memperhatikan kekuatan dan keekonomisan maka dipilih pile dengan diameter $50 \mathrm{~cm}$ dengan mengunakan free head.
\end{abstract}

Kata kunci : fix and free head, diameter $50 \mathrm{~cm}$, diameter $60 \mathrm{~cm}$, mat, ekonomis

\begin{abstract}
The need for renewable energy in Indonesia is very important, currently the source of renewable energy is relatively small. BPPT (Agency for Assessment and Application of Technology) in its activities to build a Biogas Pome pilot plant equivalent to $700 \mathrm{~kW}$ in collaboration with PTPN V (PT. Perkebunan Nusantara V) with a continuous stirred tank system in which the results of the gas are used as fuel for PMKS plant boilers in sei pagar area. The method of selecting the foundation of the reactor tank with a capacity of $2000 \mathrm{~m} 3$, we made a comparison between using free head or fix head using $50 \mathrm{~cm}$ and $60 \mathrm{~cm}$ diameters by looking at the number, pile diameter and thickness of the mat used. The planned diameter of the reactor tank is $16.8 \mathrm{~m}$ with a height of $9 \mathrm{~m}$, with a tank load of around 2174.2 tons and based on data from the soil test N-SPT values obtained at a depth of $10-15 \mathrm{~m}$, for that we formulate that the pile foundation that we choose. Comparison of fix and free head on a $50 \mathrm{~cm}$ pile size where the difference of fix and free head 44 to 65 , with a mat thickness of foundation $1.1 \mathrm{~m}$ to $0.6 \mathrm{~m}$ while using a diameter of $60 \mathrm{~cm}$ the number of piles of 32 to 50 with mat thickness $1.3 \mathrm{~m}$ to $0.6 \mathrm{~m}$. From this analysis by taking into account the strength and economics, a pile with a diameter of $50 \mathrm{~cm}$ is selected using the free head.
\end{abstract}

Keywords : fix and free head, $50 \mathrm{~cm}$ diameter, $60 \mathrm{~cm}$ diameter, mat, economical 


\section{Pendahuluan}

Continuous Stirred Tank Reactor (CSTR) adalah bioreaktor kimia yang berbentuk tabung yang berbentuk silinder dirancang untuk melakukan produksi biogas. CSTR ini adalah waktu retensi dapat diperpendek dan kontak dengan POME lebih mudah. Dengan kapasitas tangki reactor $2000 \mathrm{~m}^{3}$. Perencanaan tipe pondasi sangat lah penting, pondasi ini di desain menggunakan pondasi dalam dengan mengunakan tiang pancang dengan sistem free head atau fix head dengan melihat ekonomian dan waktu pemasangan.

\section{Tujuan Dan Keluaran}

Tujuan dari studi ini adalah:

a. Melakukan kajian perhitungan fundasi dalam dengan sistem free head dan fix head

b. Melakukan analisa ekonomian yang terbaik dalam ke 2 sistem tersebut

Keluaran Yang Ditargetkan:

a. Kajian teknis perhitungan analisa fundasi dalam free head dan fix head

b. Kajian perbandingan ekonomian antara sistem free head atau fix head

\section{Metodologi Dan Tahapan Kegiatan:}

Metodologi dan Tahapan Kegiatan yang dilakukan dalam studi kajian ini, meliputi:

a. Melakukan Studi Literatur mengenai sistim perhitungan fundasi pile dengan cara free head dan fix head;

b. Merumuskan data beban dan data tanah;

c. Melakukan perbandingan perhitungan analisa fundasi pile antara free head dengan fix head;

d. Menyusun rekomendasi dari hasil perhitungan pile free head dengan fix head dengan tetap mengikuti standar keamanan bangunan.

\section{Perencanaan Tangki Reactor CSTR Kapasitas 2000 m $^{3}$}

Pekerjaan fundasi reaktor ini terdiri dari 2 item pekerjaan antara lain :

a. Fundasi Pile

b. MAT Fundasi

Desain fondasi reaktor kapasitas $2000 \mathrm{~m}^{3}$ tahun seperti gambar di bawah ini pada gambar 1.

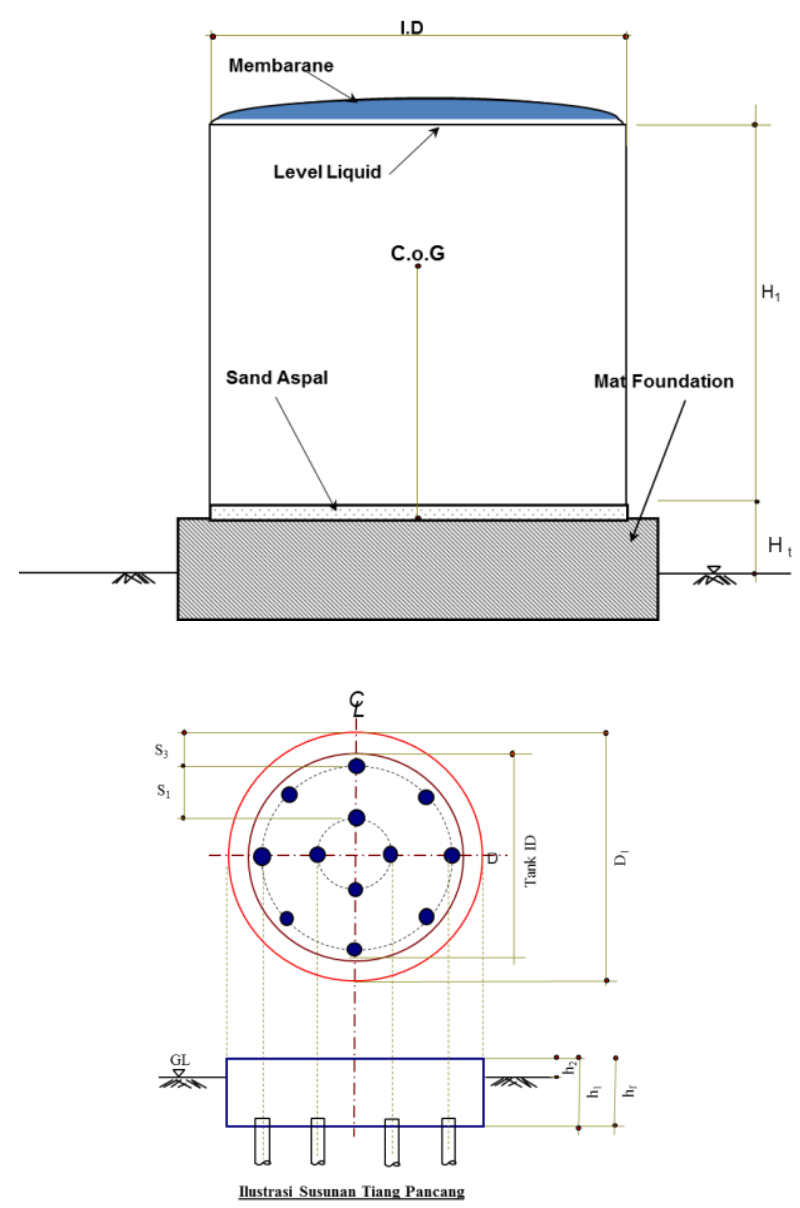

Gambar 1. Desain fundasi tangki reactor

Direncanakan diameter tangki $=16.8 \mathrm{~m}$, dengan tinggi $9 \mathrm{~m}$, dimana C.o.G $=4.5 \mathrm{~m}$. 


\section{Analisa Fundasi Pile}

Data pembebanan terdiri atas berat tangki itu sendiri dan berat saat operasional sebagai berikut:

Berat kosong $=91.8$ ton

Berat operasi $=1811.8$ ton

Berat test $=2174.2$ ton

Data rencana ukuran pondasi dengan free head dan fix head dilakukan percobaan rencana dengan menggunakan diameter pile $50 \mathrm{~cm}$ dan $60 \mathrm{~cm}$. Rencana pondasi dengan ukuran pile diameter $50 \mathrm{~cm}$ dengan free head, bisa dilihat pada gambar 2 dibawah ini:

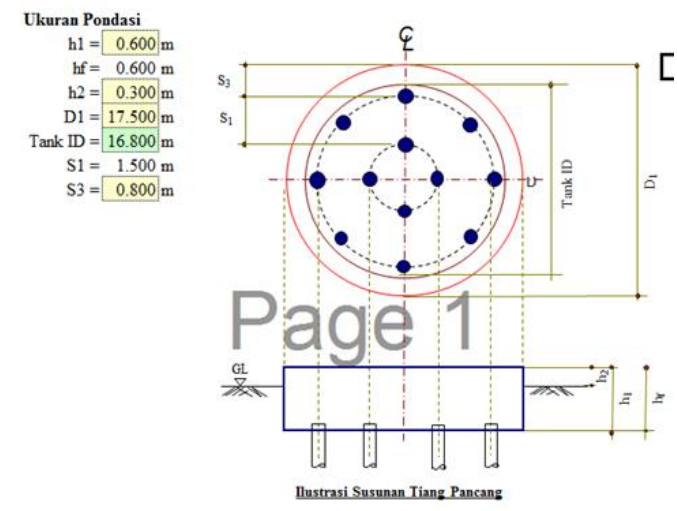

Gambar 2. Ukuran Pondasi dengan diameter $50 \mathrm{~cm}$ Free Head

Desain pondasi dengan fix head seperti pada gambar 3 dibawah ini:

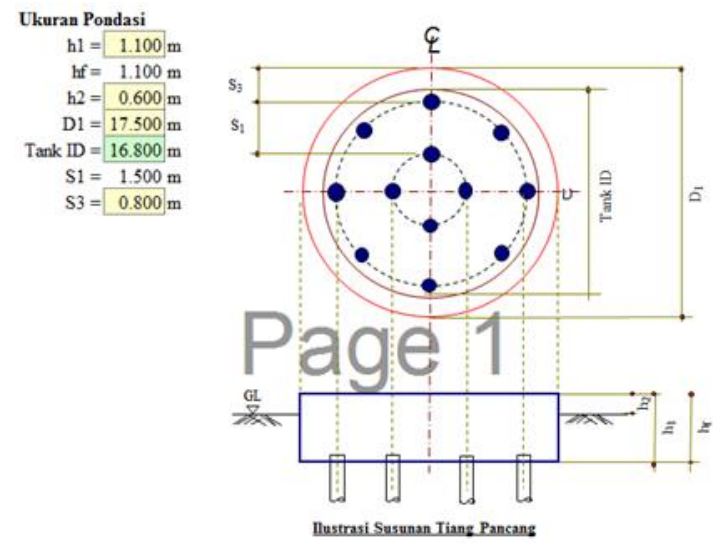

Gambar 3. Ukuran Pondasi dengan diameter $50 \mathrm{~cm}$ Fix Head
Desain pondasi diameter $60 \mathrm{~cm}$ dengan free head seperti pada gambar 4 dibawah ini:

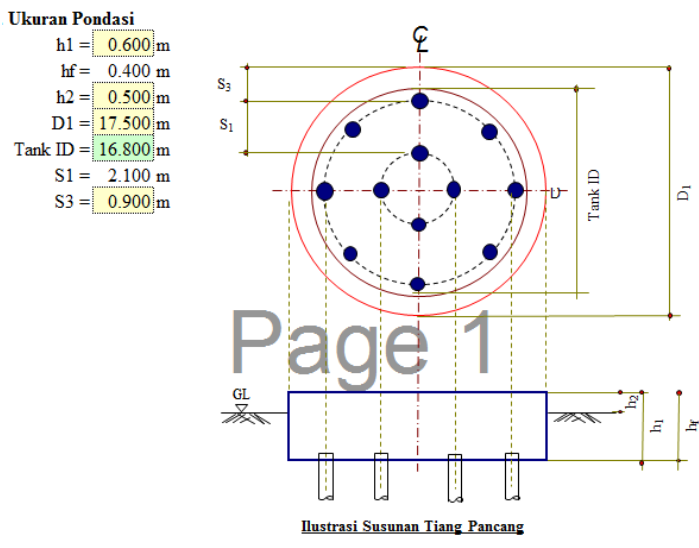

Gambar 4. Ukuran Pondasi dengan diameter $60 \mathrm{~cm}$ Free Head

Desain pondasi diameter $60 \mathrm{~cm}$ dengan fix head seperti pada gambar 5 dibawah ini:

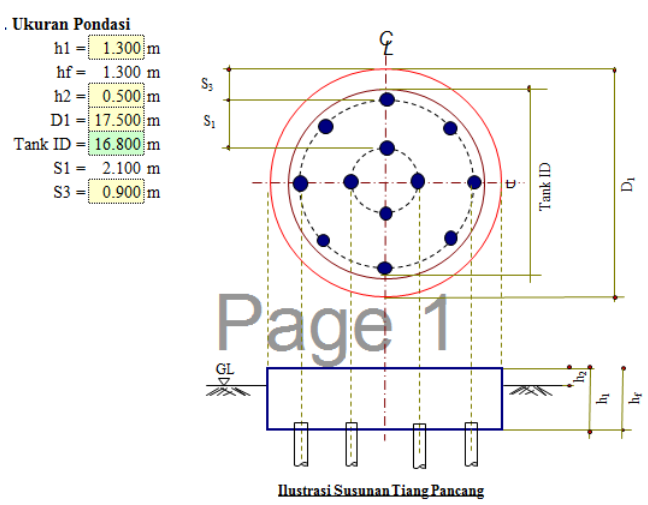

\section{Gambar 5. Ukuran Pondasi dengan diameter $60 \mathrm{~cm}$ Fix Head}

Dari rencana desain pondasi pile diameter $50 \mathrm{~cm}$ dan $60 \mathrm{~cm}$, dengan free dan fix head, didapat ukuran paling ekonomis dengan menggunakan free head dengan ketebalan pile head $60 \mathrm{~cm}$, sedangkan dengan fix head $1,1 \mathrm{~m}$ dan $1.3 \mathrm{~m}$.

\section{Analisa Perhitungan Pondasi}

Berat volume beton $(\gamma \mathrm{c})=2.40 \mathrm{t} / \mathrm{m} 3$ Berat volume tanah $(\gamma \mathrm{s})=1.70 \mathrm{t} / \mathrm{m}$ Berat Ring Wall (Wrw) $=0.0$ ton Berat Footing (Wft) $=750.45$ ton Berat tanah di atas Footing (Ws) $=0.00$ ton Total Berat Pondasi (Wf) $=\mathrm{Wrw}+\mathrm{Wft}+\mathrm{Ws}$ $=750.4$ ton 
Perhitungan Momen Guling

Momen Guling Akibat Beban Angin $(\mathrm{Mw}) \mathrm{Mw}=\mathrm{M} 1+\mathrm{H} 1 \mathrm{xhf}=41.62 \mathrm{tm}$ (Empty Condition)

Momen Guling Akibat Beban Gempa (Me)

$\mathrm{Me}=\mathrm{M} 2+\mathrm{H} 2 \mathrm{xhf}=2147.9 \mathrm{tm}$ (Operating

Condition)

Gaya Geser dan Momen Guling Akibat Gempa pada Pondasi (Mef)

Koefisien Gempa, Cs = SDS/R/I = 0.204

Hef $=$ Co $\times$ Wf $=153.39$ ton

Mef $=$ Co $\times$ Wf $\times$ hf $/ 2=99.70$ tm (Kondisi

Operasi)

Beban Kombinasi Tidak Berfaktor di Bawah Footing

1. Kosong

$$
\mathrm{D}+\mathrm{E}(\mathrm{E})
$$

2. Kosong + Angin : $\mathrm{D}+\mathrm{E}(\mathrm{E})+\mathrm{W}$

3. Normal / Operasi : $\mathrm{D}+\mathrm{E}(\mathrm{O})$

4. Normal / Operasi + Angin : $D+E(O)+W$

5. Normal / Operasi + Gempa : D + $\mathrm{E}(\mathrm{O})+\mathrm{V}$
6. Test
$\mathrm{D}+\mathrm{E}(\mathrm{T})$
7. Test + Angin :
$D+E(T)+0.25 W$

dimana :

$\mathrm{D}=$ Beban Mati $=$ Berat Pondasi $(\mathrm{Wf})$

$\mathrm{E}(\mathrm{O})=$ Beban Operasi

$\mathrm{W}=$ Beban Angin

$\mathrm{V}=$ Beban Gempa

$\mathrm{E}(\mathrm{E})=$ Kosong $/$ Erection

$\mathrm{E}(\mathrm{T})=$ Beban Test

\section{Analisa Desain Pondasi Pile}

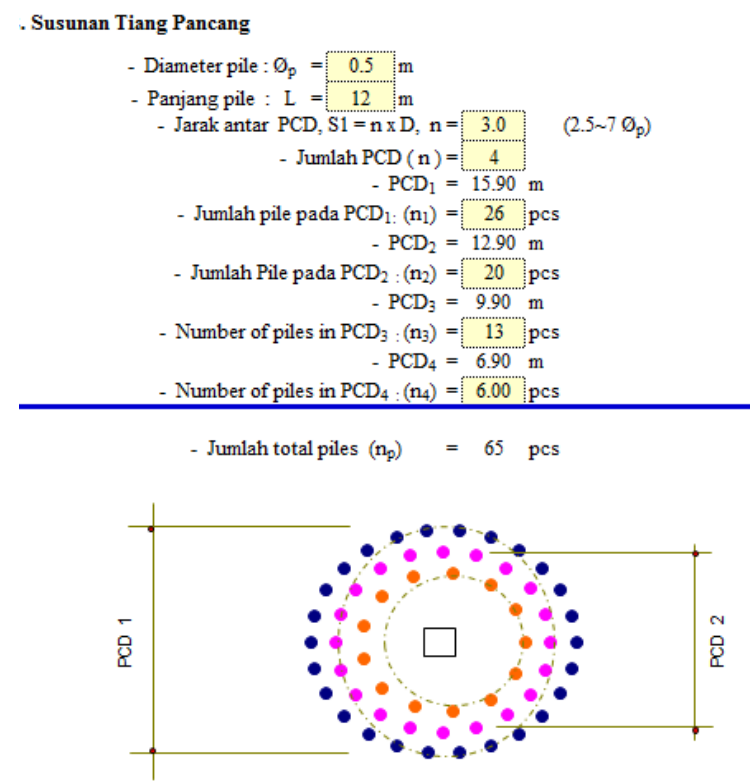

\section{Gambar 6. Analisa detail pondasi pile}

Dari rencana desain pondasi free head dengan diameter $50 \mathrm{~cm}$ didapat jumlah pile 65 pcs. Perhitungan jumlah pondasi pile dengan free dan fix head seperti pada tabel 1 dibawah ini:

Tabel 1. Jumlah Pile

\begin{tabular}{|c|c|c|}
\hline \multirow{2}{*}{$\begin{array}{c}\text { Diameter } \\
\text { Pile }\end{array}$} & \multicolumn{2}{|c|}{ Analisa Pondasi } \\
\cline { 2 - 3 } & Fix Head & Free Head \\
\hline $50 \mathrm{~cm}$ & 44 & 65 \\
\hline $60 \mathrm{~cm}$ & 32 & 50 \\
\hline
\end{tabular}

Panjang pile yang direncanakan $12 \mathrm{~m}$ berdasarkan rekomendasi dari hasil soil test.

Selanjutnya melakukan perbandingan analisa biaya dari desain yang sudah dilakukam baik menggunakan free head maupun fix head.

Dimana penawaran harga pile sampai dilokasi didapat dari PT.Kunango Jantan, Pekanbaru, Riau seperti pada tabel 2 di bawah ini: 
Tabel 2. Harga Pile

\begin{tabular}{|c|c|c|c|}
\hline Ukuran & Qty & $\begin{array}{c}\text { Harga Satuan } \\
\text { (Rp.) }\end{array}$ & $\begin{array}{c}\text { Harga Total } \\
\text { (Rp.) }\end{array}$ \\
\hline Spun Pile $50 \mathrm{~cm}$ & 44 & 596.000 & 314.688 .000 \\
\hline Spun Pile $50 \mathrm{~cm}$ & 65 & 596.000 & 387.000 .000 \\
\hline Spun Pile 60cm & 32 & 754.000 & 289.000 .000 \\
\hline Spun Pile 60cm & 50 & 754.000 & 452.000 .000 \\
\hline
\end{tabular}

Untuk harga pemancangan bisa dilihat pada tabel 3 dibawah ini:

Tabel 3. Harga Pemancangan

\begin{tabular}{|c|c|c|c|}
\hline Ukuran & Qty & $\begin{array}{c}\text { Harga Satuan } \\
\text { (Rp.) }\end{array}$ & $\begin{array}{c}\text { Harga Total } \\
\text { (Rp.) }\end{array}$ \\
\hline Spun Pile 50cm & 44 & 175.000 & 92.500 .000 \\
\hline Spun Pile 50cm & 65 & 175.000 & 136.500 .000 \\
\hline Spun Pile 60cm & 32 & 350.000 & 134.400 .000 \\
\hline Spun Pile 60cm & 50 & 350.000 & 210.000 .000 \\
\hline
\end{tabular}

Untuk harga mobilisasi alat pancang jika menggunakan diameter $50 \mathrm{~cm}$, harga angkut Rp. 40.000.000 sedangkan menggunakan alat pancang dengan menggunakan diameter $60 \mathrm{~cm}$, harga angkut Rp. 57.400.000.

Untuk harga head pile bisa dilihat pada tabel 4 dibawah ini, dengan menggunakan K250 dengan diameter tulangan $22 \mathrm{~mm}$, dimana diameter pondasi $17.5 \mathrm{~m}$.

Tabel 4. Harga Head Pile

\begin{tabular}{|c|c|c|c|}
\hline Ukuran & Qty & $\begin{array}{c}\text { Harga Satuan } \\
\text { (Rp.) }\end{array}$ & $\begin{array}{c}\text { Harga Total } \\
\text { (Rp.) }\end{array}$ \\
\hline Spun Pile $50 \mathrm{~cm}$ & $1.3 \mathrm{~m}$ & 2.328 .125 & 727.604 .541 \\
\hline Spun Pile $50 \mathrm{~cm}$ & $0.6 \mathrm{~m}$ & 2.328 .125 & 335.814 .596 \\
\hline Spun Pile $60 \mathrm{~cm}$ & $1.1 \mathrm{~m}$ & 2.328 .125 & 615.665 .381 \\
\hline Spun Pile $60 \mathrm{~cm}$ & $0.6 \mathrm{~m}$ & 2.328 .125 & 335.814 .596 \\
\hline
\end{tabular}

Dari hasil analisa rencana anggaran pekerjaan pondasi tangki reaktor bisa dapat disimpulkan pada tabel 5 dibawah ini :

Tabel 5. Perbandingan Harga Pondasi Fix Head dan Free Head

\begin{tabular}{|c|c|c|c|}
\hline Ukuran & Harga Pile & Harga Head Pile & Harga Total \\
\hline Spun Pile $50 \mathrm{~cm}$ & 407.188 .000 & 727.604 .541 & 1.134 .792 .541 \\
\hline Spun Pile $50 \mathrm{~cm}$ & 523.500 .000 & 335.814 .596 & 859.314 .000 \\
\hline Spun Pile 60cm & 423.400 .000 & 615.665 .381 & 1.040 .065 .381 \\
\hline Spun Pile 60cm & 662.000 .000 & 335.814 .596 & 997.814 .596 \\
\hline
\end{tabular}

Maka berdasarkan harga total yang akan di keluarkan dalam kegiatan pekerjaan pondasi reactor di sei pagar, Riau maka menggunakan spun pile dengan diameter $50 \mathrm{~cm}$ dengan kedalaman $12 \mathrm{~m}$ sebanyak 65 batang.

\section{Kesimpulan}

Dari kajian diatas dapat disimpulkan beberapa hal sebagai berikut:

1. Analisa pondasi yang diambil adalah diameter spun pile $50 \mathrm{~cm}$ dengan panjang $12 \mathrm{~m}$ dengan jumlah pile sebanyak 65.
2. Nilai harga total pekerjaan pondasi senilai Rp. 859.314.000.

3. Menentukan perhitungan pondasi pile apakah free head atau fix head dengan selalu memperhitungkan data yang ada dan kondisi tanah sangat lah penting dalam perencanaan yang akan di ambil lihat dari segi kekuatan struktur dan keekonomian biaya.

4. Lihat kondisi lapangan dalam perencanaan pondasi, bukan karena jumlah pile saya yang sedikit tapi biaya pemancangan sangat mempengaruhi total biaya pemancangan. 


\section{Daftar Pustaka}

SNI 2847 : 2013. Persyaratan Beton Struktural untuk Bangunan Gedung

ASCE 7-05. Minimum Design Loads for Buildings and other structures ACI 31805. Building Code Requirements for Reinforced Concrete ACI 315. Standard Practice for Detailing Concrete Structure

SNI 1726 : 2012. Tata Cara Perencanaan Ketahanan Gempa untuk Struktur Bangunan Gedung dan Non Gedung

SNI 1727 : 2013. Beban Minimum untuk Perancangan Bangunan Gedung dan Struktur Lain

SNI 2847 : 2013. Persyaratan Beton Struktural untuk Bangunan Gedung

SNI 1729 : 2015. Spesifikasi Untuk Bangunan Gedung Baja Struktural

ASME Section 8 Div.1 : Pressure Vessel

AISC-ASD 9th. Specification for the Design, Fabrication and Erection of Structure SteelforBuilding,Allowable StressDesign

Laporan Kemajuan. Konstruksi Pondasi Pilot Plant Biogas Pome 700kW. Insinas Flagship. 2019

PT Kunango Jantan. Penawaran Harga Pile, Pekanbaru 01 April 2019. 